\title{
Canadian Societies seek More Involvement
}

\section{from a Correspondent}

THE Royal Society of Canada, together with others among Canada's 119 engineering, scientific and technological societies, has been absorbed recently in a searching re-evaluation of its functions and its proper role. One sign of the society's attempts to move with the times was its sponsorship last month of a symposium on energy resources. Some observers in Ottawa are wondering whether the symposium reinforced, rather than changed, the society's public image as an ultra-conservative club for senior scientists, as the meeting was almost entirely devoid of either controversy or confrontation. It is worth recapitulating some of the background to this attempt at increased involvement.

Last December the Science Council published a study* which recommended a more active role for scientific societies in dealing with the implications of science and technology for society. It was also proposed that the federal government should establish a 'Canadian House of Science, Engineering and Technology' to provide the societies with offices and meeting space for their secretariats.

Written by Professor A. S. West, an entomologist from Queen's University, the study also noted the following difficulties facing most Canadian scientific societies:

- They are small and compete with larger counterparts in the United States; - They have low fees and small incomes, yet must cope with the expense of bilingualism;

- Their young scientists are too little involved and often have a poorly developed social conscience.

Professor West did his study under contract from the Science Council of Canada through an organisation known as SCITEC (the Asscciation of the Scientific, Engineering and Technological Community of Canada). SCITEC was formed in 1970 in response to the complaint of members of the Senate special committee on science policy (the Lamontagne Committee, see Nature, 245, 406; 1973) that they could not find a single voice to speak for all of Canadian science. It has since abandoned any pretence of fulfilling such an oracular function, but is now the principal contender, together with the Royal Society, for leadership among Canadian scientific societies.

The two societies are quite different

* National Engineering, Scientific and Technological Societies of Canada, A. S. West, Science Council Special Study No. 25. in purpose and structure. The Royal Society is the Canadian equivalent of an academy of science, but SCITEC is somewhat analogous to the British or American Associations for the Advancement of Science. Both groups claim, however, some similar functions. One of these is to increase public understanding of scientific issues; SCITEC itself had already held a symposium on the social and economic implications of the energy situation.

The report of the Lamontagne Committee proposed that the two organisations should not compete but cooperate, by defining and dividing their functions. "The Royal Society," it said, "with its reservoir of scholarship represented by its fellows and scientific panels could concentrate its national activities on the use of science for policy-on scientific and technological studies dealing with Canadian issues. SCITEC, as an overall spokesman for the engineering, scientific and technological societies, could specialise on policies for science and technology-on broad issues concerning scientists, engineers, and technologists in the exercise of their professions."

The Royal Society's latest symposium, however, seems to some to cast doubt on the claim of its president of last year, Professor Tuzo Wilson, that the organisation is being revitalised. For although the subject matter (energy) was highly topical, the approach and the choice of

\section{MEDICAL JURISPRUDENCE Transplants and Murder}

by our Washington Correspondent A Murder trial which is to open in California on December 18 will be the venue for a legal battle over the precise definition of death, and the outcome will have significant implications for transplant surgery. At the centre of the trial is Andrew D. Lyons, who is accused of shooting Samuel Moore, a 29-year-old California man, in the head on September 10,1973. On September $12 \mathrm{Mr}$ Moore's brain showed no signs of electrical activity, he was unable to breathe, and did not respond to stimulation. He was then pronounced "neurologically dead", and his heart was used in a transplant operation performed by Dr Norman Shumway, a Stanford heart surgeon who has performed some 65 transplants; 23 of his patients are still surviving.

Californian law allows transplants to be performed provided that the donor has been pronounced dead, but no pre- speakers and subjects seemed conventional and the papers added nothing new to an already much-debated problem. What little discussion was allowed, was conducted by means of written questions; a practice that brought a formal complaint from some of the younger members of the audience.

There were some good things. The society took unusual steps to publicise the venture and had a good attendance as a result (some 300). The review papers provided a mass of information. And three of the thirty-five speakers departed from the predominant themehow to increase the energy supply-by proposing that perhaps what is needed is a whole new policy of moderation of life styles to slow down the rate of increase in the use of energy. One of the three was former chairman of the Economic Council of Canada, John $\mathbf{J}$. Deutsch.

In his report, Professor West spoke of the need of a major overall coordinating organisation to increase the involvement of Canadian scientific societies, and he quoted an unnamed scientist as saying it must be "of such stature and articulation that the public will accept its pronouncements on the same plane at least as those of the Science Council."

The impression remains that, in spite of recent attempts, neither society has yet succeeded in fulfilling that role.

cise legal definition of death is given. In this case, according to the New York Times, Moore's wife and mother had given permission for the transplant, Moore was pronounced dead on the grounds of a lack of cortical activity, and his heart was removed while still beating. Clearly, the concept of brain death is going to play a large part in the trial. There is, however, one close parallel case in American legal history. Last year, a team of surgeons from the Medical College of Virginia was acquitted of a charge of killing a 56year-old black man to use his heart in a transplant operation. In that case the donor suffered brain damage as the result of a fall, and he was pronounced dead when an electroencephalogram showed no signs of electrical activity in the brain. His heart was subsequently removed, while still beating, and used in the first heart transplant carried out in Virginia. The jury in the trial had little difficulty in deciding that the donor was legally dead when his heart was removed, and the doctors were acquitted. 